\title{
Dysregulation of the adipoinsular axis - a mechanism for the pathogenesis of hyperleptinemia and adipogenic diabetes induced by fetal programming
}

\author{
M H Vickers, S Reddy, B A Ikenasio and B H Breier \\ Liggins Institute for Medical Research, Faculty of Medical and Health Sciences, University of Auckland, Auckland, New Zealand \\ (Requests for offprints should be addressed to B H Breier, Liggins Institute for Medical Research, Faculty of Medical and Health Sciences, The University of \\ Auckland, Private Bag 92019, Auckland, New Zealand; Email: bh.breier@auckland.ac.nz)
}

\begin{abstract}
Obesity and its related disorders are the most prevalent health problems in the Western world. Using the paradigm of fetal programming we developed a rodent model which displays the phenotype of obesity and metabolic disorders commonly observed in human populations. We apply maternal undernutrition throughout gestation, generating a nutrient-deprived intrauterine environment to induce fetal programming. Maternal undernutrition results in fetal growth retardation and in significantly decreased body weight at birth. Programmed offspring develop hyperphagia, obesity, hypertension, hyperleptinemia and hyperinsulinism during adult life and postnatal hypercaloric nutrition amplifies the metabolic abnormalities induced by fetal programming. The adipoinsular axis has been proposed as a primary candidate for linking the status of body fat mass to the function of the pancreatic $\beta$-cells. We therefore investigated the relationship between circulating plasma concentrations of leptin and insulin and immunoreactivity in the endocrine pancreas for leptin and leptin receptor (OB-R) in genetically normal rats that were programmed to become obese during adult life. Virgin Wistar rats were time mated and randomly assigned to receive food either available ad libitum (AD group) or at $30 \%$ of the ad libitum available intake (UN group). Offspring from UN mothers were significantly smaller at birth than AD offspring (AD 6.13 $\pm 0.04 \mathrm{~g}$, UN $4.02 \pm 0.03 \mathrm{~g}, \quad P<0 \cdot 001)$. At weaning, offspring were
\end{abstract}

assigned to one of two diets (a standard control diet or a hypercaloric diet consisting of 30\% fat) for the remainder of the study. At the time of death (125 days of age), UN offspring had elevated $(P<0 \cdot 005)$ fasting plasma insulin (AD control $1.417 \pm 0.15 \mathrm{ng} / \mathrm{ml}$, UN control $2.493 \pm 0.33 \mathrm{ng} / \mathrm{ml}$, AD hypercaloric $1.70 \pm 0.17 \mathrm{ng} / \mathrm{ml}$, UN hypercaloric $2 \cdot 608 \pm 0 \cdot 41 \mathrm{ng} / \mathrm{ml}$ ) and leptin (AD control $8.8 \pm 1.6 \mathrm{ng} / \mathrm{ml}$, UN control $14.32 \pm 1.9 \mathrm{ng} / \mathrm{ml}$, AD hypercaloric $15 \cdot 11 \pm 1.8 \mathrm{ng} / \mathrm{ml}$, UN hypercaloric $30 \cdot 18 \pm 5 \cdot 3 \mathrm{ng} / \mathrm{ml})$ concentrations, which were further increased $(P<0 \cdot 05)$ by postnatal hypercaloric nutrition. The elevated plasma insulin and leptin concentrations were paralleled by increased immunolabeling for leptin in the peripheral cells of the pancreatic islets. Dual immunofluorescence histochemistry for somatostatin and leptin revealed that leptin was co-localized in the pancreatic $\delta$-cells. OB-R immunoreactivity was evenly distributed throughout the pancreatic islets and was not changed by programming nor hypercaloric nutrition. Our data suggest that reduced substrate supply during fetal development can trigger permanent dysregulation of the adipoinsular feedback system leading to hyperleptinemia, hyperinsulinism and compensatory leptin production by pancreatic $\delta$-cells in a further attempt to reduce insulin hypersecretion in the progression to adipogenic diabetes.

Journal of Endocrinology (2001) 170, 323-332

\section{Introduction}

Hyperinsulinism is one of the earliest metabolic indicators of obesity and type 2 diabetes (Chen et al. 1997). In the $o b / o b$ mouse, the primary cause of obesity is due to a mutation in the $o b$ gene and the absence of circulating leptin has been postulated to be the missing signal to the pancreatic islets which normally prevents the hypersecretion of insulin (Fehmann et al. 1997a, Girard 1997, Poitout et al. 1998). The presence of functional receptors for leptin on insulin-secreting $\beta$-cells (Kieffer et al. 1996, Fehmann et al. 1997b) and the observation that leptin directly inhibits insulin secretion (Emilsson et al. 1997, Ishida et al. 1997) led to the concept of an interrelated endocrine insulin-leptin feedback system termed the adipoinsular axis (Kieffer \& Habener 2000). In this concept, insulin stimulates adipogenesis and leptin production in adipocytes whilst leptin inhibits the production of insulin in pancreatic $\beta$-cells. As fat stores increase, rising plasma leptin concentrations reduce circulating insulin 
levels, thereby directing less energy to the formation of adipose tissue. When, on the other hand, adipose stores decrease, falling plasma leptin concentrations permit increased insulin production, thereby resulting in the deposition of additional fat. The negative feedback of leptin on insulin gene transcription and insulin secretion in pancreatic islets is well established (Ceddia et al. 1999, Lupi et al. 1999, Seufert et al. 1999a). However, more recent evidence suggests that defective leptin reception by pancreatic $\beta$-cells may be a key mechanism for obesity-associated hyperinsulinism and may contribute to the pathogenesis of adipogenic diabetes (Seufert et al. 1999b).

Maternal malnutrition during pregnancy has previously been shown to result in the development of obesity in offspring (Anguita et al. 1993, Jones et al. 1995, Jackson et al. 1996). We have developed an animal model of adult obesity using the paradigm of fetal programming by maternal undernutrition throughout pregnancy. The fetal programming hypothesis proposes that an adverse intrauterine environment alters the fetal metabolic and hormonal milieu, resulting in developmental adaptations to ensure fetal survival (Barker 1995). If these adaptive responses, designed for survival in a substrate-limited fetal environment, persist into postnatal life, it is proposed that they lead to metabolic and endocrine disorders. We have recently shown that programmed offspring develop hyperphagia, obesity and hypertension as adults whilst hypercaloric nutrition amplifies the metabolic and cardiovascular disorders induced by fetal programming (Vickers et al. 2000). Similar to observations in human obesity, programmed offspring develop hyperleptinemia and hyperinsulinism. Hyperleptinemia and hyperinsulinism have been linked with leptin resistance at the level both of the hypothalamus and of the pancreatic $\beta$-cells - the latter has been postulated as a key mechanism in the pathogenesis of adipogenic diabetes mellitus (Kieffer \& Habener 2000). Mechanisms underlying leptin resistance are thought to include abnormalities of leptin receptors (OB-R) and post-receptor signaling (Ahima \& Flier 2000). While it is well established that the absence of circulating leptin leads to obesity, hyperphagia and hyperinsulinism (Sindelar et al. 1999), more recent evidence suggests that dysregulation of the adipoinsular axis and the corresponding failure of rising plasma leptin levels to suppress insulin secretion, results in chronic hyperinsulinism and obesity (Kieffer \& Habener 2000).

The aim of this study was to investigate the relationship between circulating plasma concentrations of insulin and leptin, and immunoreactivity in the endocrine pancreas for leptin and OB-R in genetically normal rats that were programmed to become obese during adult life. Our data suggest that reduced substrate supply during fetal development can trigger permanent dysregulation of the adipoinsular feedback system leading to compensatory leptin production by pancreatic $\delta$-cells in a final attempt to reduce insulin hypersecretion in the progression to adipogenic diabetes.

\section{Materials and Methods}

\section{Animal model}

Virgin Wistar rats (aged $100 \pm 5$ days) were time mated using a rat estrous cycle monitor to assess the stage of estrus of the animals prior to introducing the male. After confirmation of mating, rats were housed individually in standard rat cages containing wood shavings as bedding and had free access to water. All rats were kept in the same room with a constant temperature maintained at $25^{\circ} \mathrm{C}$ and a 12-h light:12-h darkness cycle. Animals were assigned to one of two nutritional groups ( $n=16$ per group): one group received a standard diet available ad libitum throughout gestation (AD group); the second group was undernourished receiving 30\% of the ad libitum available food of the standard diet throughout gestation (UN group). Food intake and maternal weights were recorded daily until parturition. After birth, pups were weighed and litter size was recorded. Pups from UN mothers were cross-fostered onto dams which received $\mathrm{AD}$ feeding throughout pregnancy.

Litter size was adjusted to 8 pups per litter to ensure adequate and standardized nutrition until weaning. After weaning, male offspring from $\mathrm{AD}$ and UN mothers were further divided into two balanced postnatal groups ( $n=6$ per group) to be fed either a standard diet (protein $19.9 \%$, fat $5 \%$, digestible energy $3504 \mathrm{kcal} / \mathrm{kg}$, protein energy/total energy $22 \cdot 7 \%$ ) or a hypercaloric diet (protein 28.5\%, fat 30\%, digestible energy $4922 \mathrm{kcal} / \mathrm{kg}$, protein energy/total energy $22 \cdot 7 \%$ ). The mineral and vitamin contents in the two diets were identical and in accordance with the requirements for standard rat diets. At day 125, rats were fasted overnight and killed by halothane anesthesia followed by decapitation. Blood was collected into heparinized vacutainers and stored on ice until centrifugation and removal of the supernatant for analysis. Pancreatic tissue was removed and stored in Bouin's solution until processing and embedding in paraffin. The Animal Ethics Committee of the University of Auckland approved all animal work.

\section{Immunohistochemistry for leptin}

Immunohistochemistry was performed using the avidinbiotin (ABC) method for immunostaining of paraffinembedded sections (Vectastain Elite Kit (Vector Laboratories, Burlingame, CA, USA), rabbit immunoglobulin $\mathrm{G}$ (IgG), PK-6101). In brief, $4 \mu \mathrm{m}$ sections were deparaffinized and treated with $1 \% \mathrm{H}_{2} \mathrm{O}_{2}$ in methanol for $30 \mathrm{~min}$ at room temperature to inhibit endogenous peroxidase activity. Sections were then washed and 
incubated with $1.5 \%$ normal goat serum at room temperature for $30 \mathrm{~min}$. Samples were incubated for $48 \mathrm{~h}$ at $4{ }^{\circ} \mathrm{C}$ with our polyclonal antibody (1:5000) raised against a synthetic fragment (amino acids (aa) 30-45) of bovine leptin. After a further washing step, sections were incubated for $2 \mathrm{~h}$ at room temperature with a biotinylated secondary antiserum (goat anti-rabbit $\operatorname{IgG}$ biotin). After washing, sections were incubated for $1 \mathrm{~h}$ at room temperature with an avidin-biotin peroxidase complex. Following addition of diaminobenzidine (DAB), sections were washed and counterstained. Sections were then dehydrated and mounted with Surgipath (Surgipath Instruments, Richmond, IL, USA). Normal rabbit serum and antiserum preabsorbed with excess recombinant mouse (rm)-leptin (Crystalchem, Chicago, IL, USA, \#CR-6781) were used as negative controls.

\section{Immunohistochemistry for leptin receptor}

Immunohistochemistry for the leptin receptor (OB-R) was performed using the $\mathrm{ABC}$ method for immunostaining of paraffin-embedded sections (Vectastain Elite Kit, goat $\operatorname{IgG}, \mathrm{PK}-6105)$. In brief, 4- $\mu \mathrm{m}$ sections were deparaffinized and treated with $1 \% \mathrm{H}_{2} \mathrm{O}_{2}$ in methanol for $30 \mathrm{~min}$ to inhibit endogenous peroxidase activity. Sections were then washed and incubated with 5\% normal rabbit serum for $1 \mathrm{~h}$ at room temperature. Samples were incubated for $24 \mathrm{~h}$ at $4{ }^{\circ} \mathrm{C}$ with primary antibody (1:40). Two leptin receptor antibodies were utilized: (i) raised against peptides corresponding to amino acid residues 32 to 51 mapping at the amino terminus of the OB-R of mouse origin and (ii) raised against a peptide corresponding to amino acid residues 877 to 894 mapping at the carboxy terminus of the OB-R of mouse origin (cat. \# RDI-RTOBRECPCabg and RDI-RTOBRECONabg respectively, Research Diagnostics, Inc, Flanders, NJ, USA). After washing, sections were incubated for $2 \mathrm{~h}$ at room temperature with a biotinylated secondary antiserum (goat anti-rabbit IgG biotin). After washing, sections were incubated for $1 \mathrm{~h}$ at room temperature with an avidinbiotin peroxidase complex. Following addition of DAB, sections were washed and counterstained. Sections were then dehydrated and mounted with Surgipath (Surgipath Instruments). Normal goat serum and pre-absorbed primary antibody with 10-fold excess of peptide antigen (Research Diagnostics, cat. \# RDI-RTOBRECPC-CP and RTOBRECPN-CP for each respective antibody) were used as negative controls.

\section{Dual label immunofluorescence staining for somatostatin and leptin}

Following blocking with 5\% normal donkey serum (1 h, $37^{\circ} \mathrm{C}$ ), sections were incubated with primary antibody (monoclonal, mouse anti-somatostatin, 1:10, Novo Nordisk, Copenhagen, Denmark) for $1 \mathrm{~h}$ at $37^{\circ} \mathrm{C}$.
Following washing in PBS $(0 \cdot 01 \mathrm{M})$, sections were incubated with donkey anti-mouse IgG-Texas Red for $1 \mathrm{~h}$ at $37^{\circ} \mathrm{C}(1: 100$, Jackson Immunoresearch Laboratories, Pine Grove, PA, USA). Sections were washed in PBS, blocked with $5 \%$ normal goat serum for $1 \mathrm{~h}$ at room temperature, followed by incubation for $24 \mathrm{~h}$ at $4{ }^{\circ} \mathrm{C}$ with anti-leptin antibody as described above. After washing, sections were incubated for $2 \mathrm{~h}$ at $37^{\circ} \mathrm{C}$ with goat anti-rabbit $\operatorname{IgG}$ biotin. Sections were then incubated for $1 \mathrm{~h}$ at $37^{\circ} \mathrm{C}$ with streptavidin-fluorescein isothiocyanate (Jackson Immunoresearch Laboratories). After washing, sections were mounted with PBS/glycerol, and examined with an Olympus UV-visible microscope equipped with excitation filters for Texas Red $(568 \mathrm{~nm})$ and fluoroscein (488 nm).

\section{Radioimmunoassays for insulin and leptin}

Fasting plasma insulin was measured by radioimmunoassay (RIA) as described previously (Woodall et al. 1996) and validated for measurement of insulin in rat plasma samples (Lewis et al. 1999). A double antibody RIA was developed and validated for measurement of leptin in rat plasma. An antibody was raised in rabbits against a synthetic fragment (aa 30-45) of bovine leptin. The standard preparation for the RIA was rm-leptin (Crystalchem, \#CR-6781) used in concentrations ranging from 0.5 to $20 \mathrm{ng} / \mathrm{ml}$. Samples were assayed neat or diluted $1: 2-1: 4$ in assay buffer ( $0 \cdot 05 \mathrm{M}$ PBS, pH $7 \cdot 4$ containing $0 \cdot 1 \mathrm{M} \mathrm{NaCl}, 0 \cdot 5 \% \mathrm{BSA}$, $10 \mathrm{mM}$ EDTA, $0 \cdot 05 \% \mathrm{NaN}_{3}$ ). In brief, $100 \mu \mathrm{l}$ primary antibody (1:25 000) were added to tubes containing $100 \mu \mathrm{l}$ sample or standard. Following incubation for $24 \mathrm{~h}$ at $4{ }^{\circ} \mathrm{C}$, $100 \mu \mathrm{l}$ tracer $\left({ }^{125} \mathrm{I}\right.$-rm-leptin, 20000 c.p.m. per tube) were added to all tubes followed by incubation for $24 \mathrm{~h}$ at $4{ }^{\circ} \mathrm{C}$. A second antibody was used to separate bound from free ligands (Breier et al. 1996). Rat plasma samples showed parallel displacement to the standard curve and recovery of unlabeled rm-leptin was $101 \cdot 4 \pm 2 \cdot 7 \%$ (mean \pm s.E.M., $n=26$ ). The half-maximally effective dose, $\mathrm{ED}_{50}$, was $3.7 \mathrm{ng} / \mathrm{ml}$ and the intra-assay coefficient of variation was $<5 \%$ (all samples were measured within a single assay).

\section{Plasma glucose concentrations}

Fasting plasma glucose concentrations were measured using a YSI Glucose Analyzer (Model 2300, Yellow Springs Instrument Co., Yellow Springs, OH, USA).

\section{Statistical analysis}

Statistical analyses were carried out using a StatView statistical package (version 5, SAS Institute, Cary, NC, USA). Differences between groups were determined by 


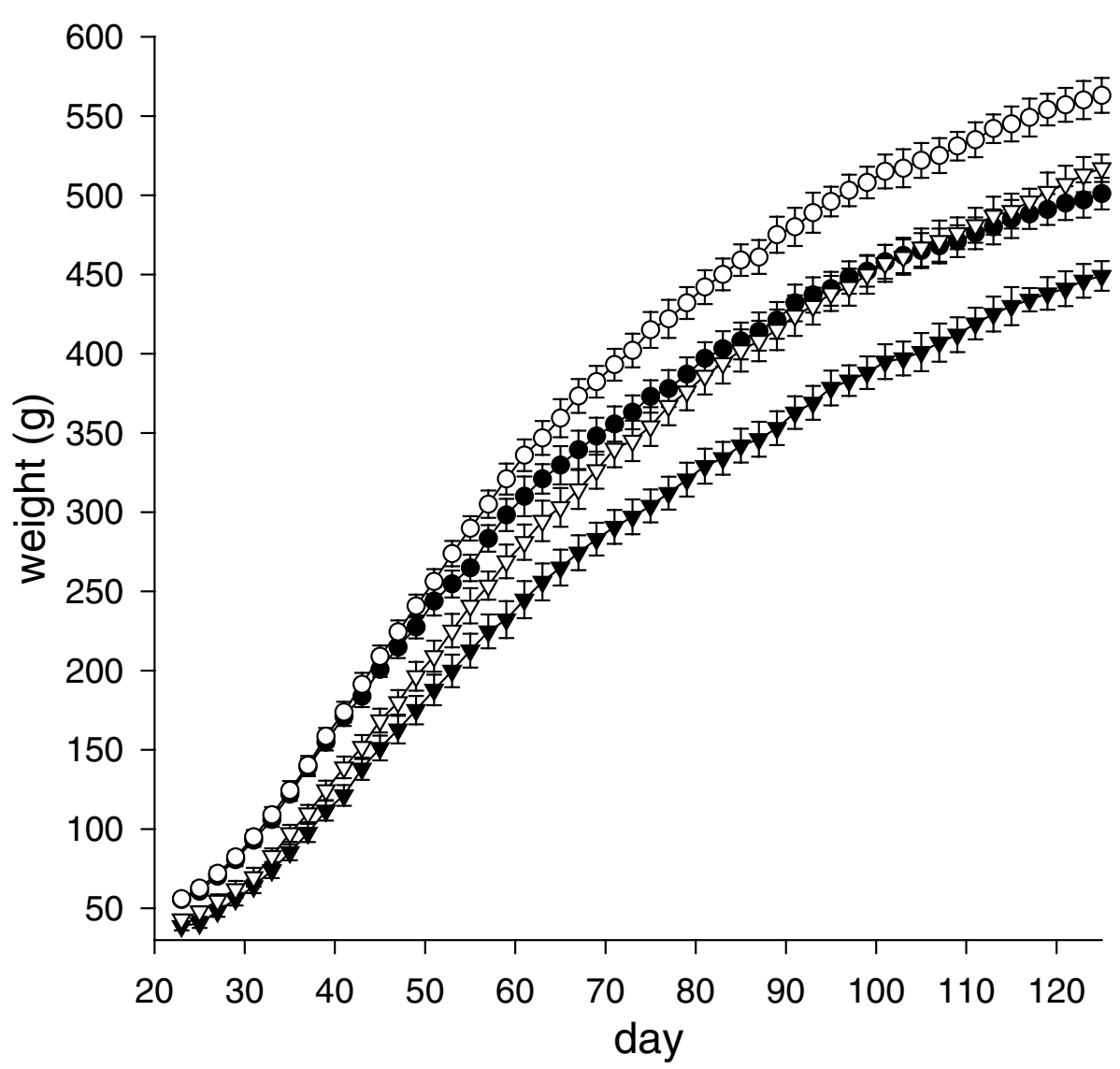

Figure 1 Postnatal growth curves of male offspring from weaning until day $120 \bullet$, AD animals fed a control diet; $\bigcirc, \mathrm{AD}$ animals fed a hypercaloric diet; $\boldsymbol{\nabla}$, UN animals fed a control diet; $\nabla$, $U N$ animals fed a hypercaloric diet). Data represent means \pm S.E.M. with $n=6$ animals per group. UN offspring on the hypercaloric diet show apparent catch-up growth in body weight by postnatal day 125.

two-way ANOVA and data are shown as means \pm s.E.M. Statistical significance was accepted at the $P<0.05$ level.

\section{Results}

Maternal undernutrition resulted in fetal growth retardation reflected by significantly $(P<0 \cdot 001)$ decreased body weights at birth in offspring from UN dams (AD $6 \cdot 13 \pm 0.04 \mathrm{~g}$, UN $4 \cdot 02 \pm 0.03 \mathrm{~g})$. Litter size did not differ between the two groups (AD 13.6 $\pm 0 \cdot 6$, UN $12 \cdot 6 \pm 1 \cdot 1)$. Total body weights on both diets remained significantly lower in UN offspring throughout the study. However, by postnatal day 125, programmed offspring (from UN mothers) on the hypercaloric diet showed apparent catch-up in body weight and matched the weights of $\mathrm{AD}$ animals fed the control diet (Fig. 1). Nose-anus lengths were significantly $(P<0 \cdot 05)$ shorter in UN offspring at 125 days of age (AD control $196 \pm 2 \cdot 8 \mathrm{~mm}$, AD hypercaloric $201 \pm 4 \cdot 5 \mathrm{~mm}$, UN con- trol $187 \pm 5.7 \mathrm{~mm}$, UN hypercaloric $189 \pm 2.7 \mathrm{~mm}$ ). Postnatal hypercaloric nutrition significantly $(P<0 \cdot 05)$ increased body weights as compared with control-fed animals in both UN and AD offspring (Fig. 1). Food intake (calories consumed per gram body weight) calculated over the last three weeks of the study was increased $(P<0 \cdot 001)$ in UN offspring and further increased $(P<0 \cdot 001)$ by hypercaloric nutrition (AD control $0 \cdot 18 \pm 0 \cdot 003$, AD hypercaloric $0 \cdot 21 \pm 0 \cdot 002$, UN control $0 \cdot 22 \pm 0 \cdot 002$, UN hypercaloric $0 \cdot 25 \pm 0 \cdot 001)$. There were no significant statistical interactions between programming and diet.

The increase in food intake was paralleled by a significant increase in circulating plasma leptin and insulin concentrations in UN animals and by hypercaloric nutrition (Fig. 2A,B). Fasting plasma insulin concentrations were significantly $(P<0 \cdot 05)$ increased by programming and by hypercaloric nutrition; both effects were additive but there was no statistical interaction. However, two-way ANOVA of plasma leptin data revealed a significant 

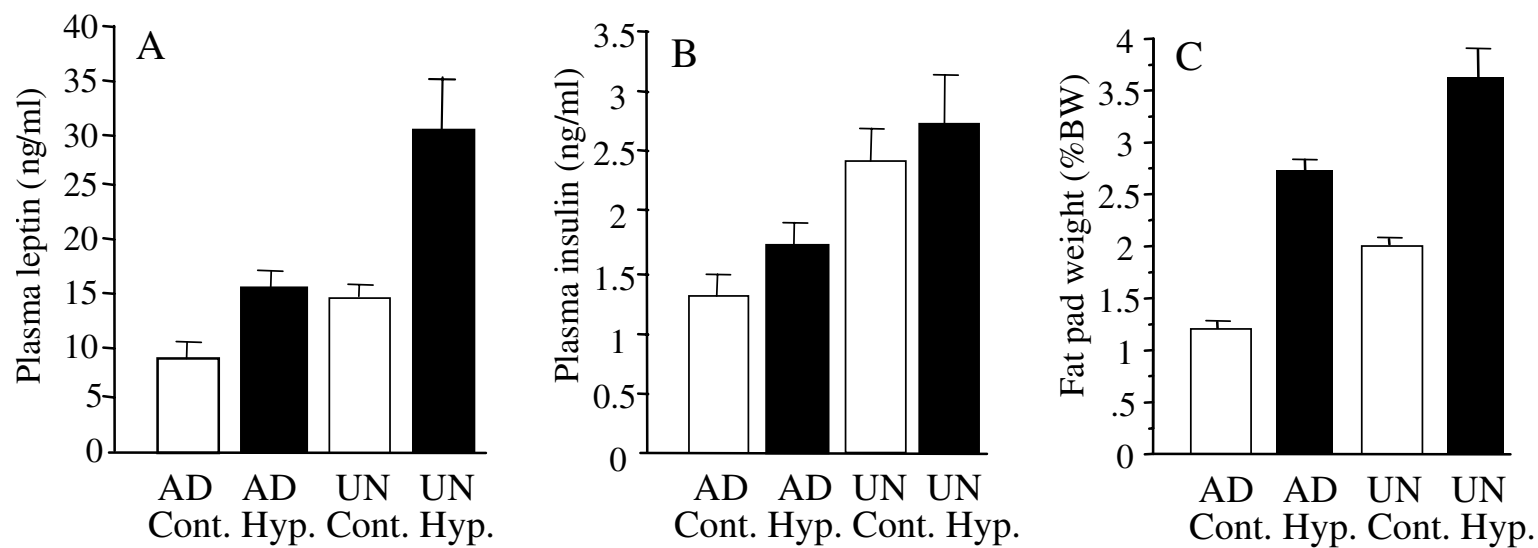

Figure 2 Fasting plasma leptin (A), insulin (B), and retroperitoneal fat pad mass (expressed as a percentage of body weight $(B W))(C)$ at postnatal day 125 in $\mathrm{AD}$ and $U N$ offspring fed the control (Cont.) or hypercaloric (Hyp.) diet postnatally. Leptin: effect of programming $P<0.005$; effect of diet $P<0.0005$; programming and diet interaction $P<0.05$. Insulin: effect of programming $P<0.05$; effect of diet $P<0 \cdot 05$. Retroperitoneal fat pad: effect of programming $P<0 \cdot 005$; effect of diet $P<0 \cdot 0001$. No interactions were present between programming and diet for either fasting plasma insulin or fat pad weights. Data are presented as means \pm S.E.M., $n=6$ animals per group.

programming-diet interaction $(P<0 \cdot 05)$, suggesting that the programming-induced hyperleptinemia is amplified by diet-induced obesity. Retroperitoneal fat pad weight relative to body weight was significantly $(P<0 \cdot 05)$ increased in UN offspring, and hypercaloric nutrition further increased fat pad weight in both $\mathrm{AD}$ and UN offspring $(P<0 \cdot 001$, Fig. 2C). Fasting plasma glucose concentrations were not different between $\mathrm{AD}$ and $\mathrm{UN}$ groups fed a standard diet. However, fasting plasma glucose concentrations were significantly elevated $(P<0 \cdot 05)$ in hypercalorically fed offspring, leading to hyperglycemia in programmed offspring exposed to diet-induced obesity (AD control diet $7 \cdot 44 \pm 0.44 \mathrm{mmol} /$ 1, AD hypercaloric diet $8.82 \pm 0.42 \mathrm{mmol} / 1$, UN control diet $8.43 \pm 0.48 \mathrm{mmol} / \mathrm{l}$, UN hypercaloric diet $9 \cdot 19 \pm 0 \cdot 48 \mathrm{mmol} / \mathrm{l})$.

Immunohistochemistry was performed on three randomly selected animals per group with a minimum of six islets examined per animal. The figures shown are representative examples of all immunohistochemistry studies for each group presented below. Immunohistochemistry showed that only a few cells were immunopositive for leptin in 125-day-old AD offspring fed the control diet (Fig. 3A). Diet-induced obesity caused a small increase in cells which were immunoreactive for leptin in $\mathrm{AD}$ offspring which received hypercaloric nutrition (Fig. 3B). However, the number of cells showing leptin immunolabeling was increased in pancreatic islets of rats which were programmed to become obese as a result of maternal undernutrition (Fig. 3C). Leptin immunoreactivity in pancreatic islets of UN offspring was further upregulated by hypercaloric nutrition (Fig. 3D and F). There was an absence of immunolabeling in control sections incubated with either normal rabbit serum or primary antiserum pre-absorbed with excess leptin (Fig. 3E).

While both fetal programming and hypercaloric nutrition increased immunoreactive leptin localization in the periphery of the endocrine islet, immunoreactive OB-R was evenly distributed throughout the endocrine islet and no difference was observed between any of the experimental groups studied (Fig. 4A, B, D and E). The two different antibodies for OB-R showed identical results in immunolabeling for the OB-R (data not shown). Immunostaining for OB-R was absent following preabsorption (Fig. 4C). Using dual label immunofluorescence, leptin and somatostatin were found to be co-expressed in the periphery of the endocrine islet, thus strongly suggesting that leptin may be produced by pancreatic $\delta$-cells (Fig. 5A and B).

\section{Discussion}

Obesity and related disorders are the most prevalent health problems in the Western world. Although the risk of type 2 diabetes is high in obese subjects, glucose homeostasis remains relatively normal for long periods of time despite the development of hyperinsulinism or insulin resistance and continuation of excessive food intake. The ability to maintain euglycemia despite increased insulin requirements is achieved by increased insulin production (Echwald et al. 1999). The metabolic or hormonal mechanisms of obesity-associated hyperinsulinism by which the pancreatic islets attempt to regulate an increased demand for insulin are unknown.

The adipoinsular axis is a primary candidate for linking the status of body fat mass to the function of the pancreatic 

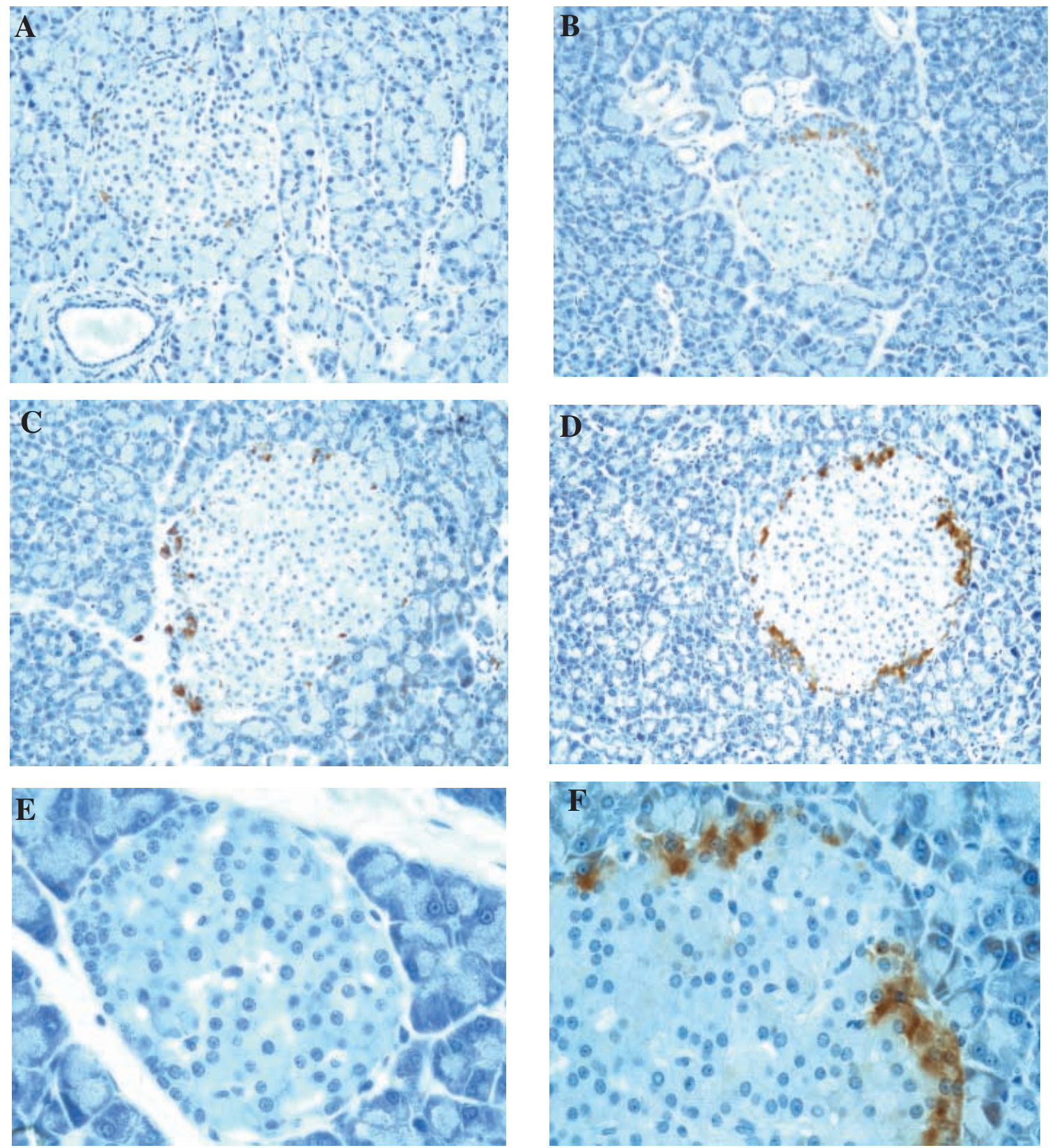

Figure 3 Representative images showing immunohistochemical localization of leptin in pancreatic islets in (A) AD animals fed a control diet, (B) AD animals fed a hypercaloric diet, (C) UN animals fed a control diet, (D) UN animals fed a hypercaloric diet, (E) absence of staining in an islet following leptin antibody preabsorption with 10-fold excess of control peptide and (F) higher magnification of (D). All images are $\times 250$ magnification with the exception of $(E$ and $F)$ which are $\times 630$.

$\beta$-cells (Kieffer \& Habener 2000). While a number of in vitro studies have yielded controversial results for the effects of leptin on insulin secretion (Leclercq-Meyer et al. 1996, Ahren \& Harvel 1999, Ceddia et al. 1999, Lupi et al. 1999), there is now convincing evidence in vitro and in vivo that leptin suppresses insulin secretion and gene expression in pancreatic islets (Emilsson et al. 1997, Poitout et al.
1998, Seufert et al. 1999a,b). These studies show that leptin suppresses insulin production from pancreatic $\beta$-cells and the presence of OB-R on pancreatic $\beta$-cells suggests a functional relationship between circulating leptin and insulin secretion. Since insulin is adipogenic and increases the expression of leptin in adipose tissue, the bi-directional feedback loop between adipose tissue and pancreatic islets 


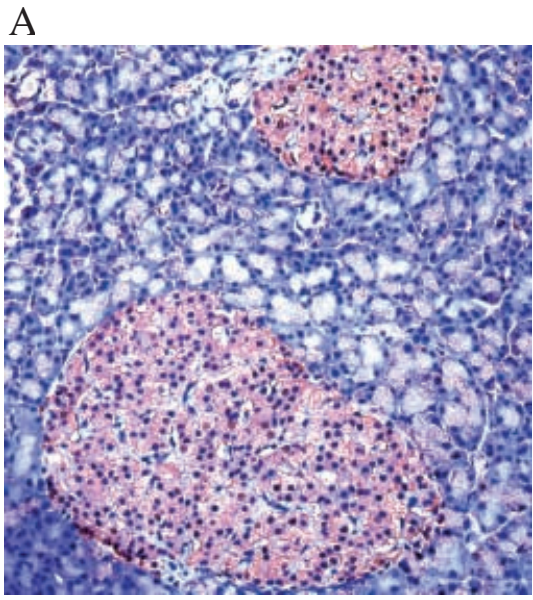

$\mathrm{D}$

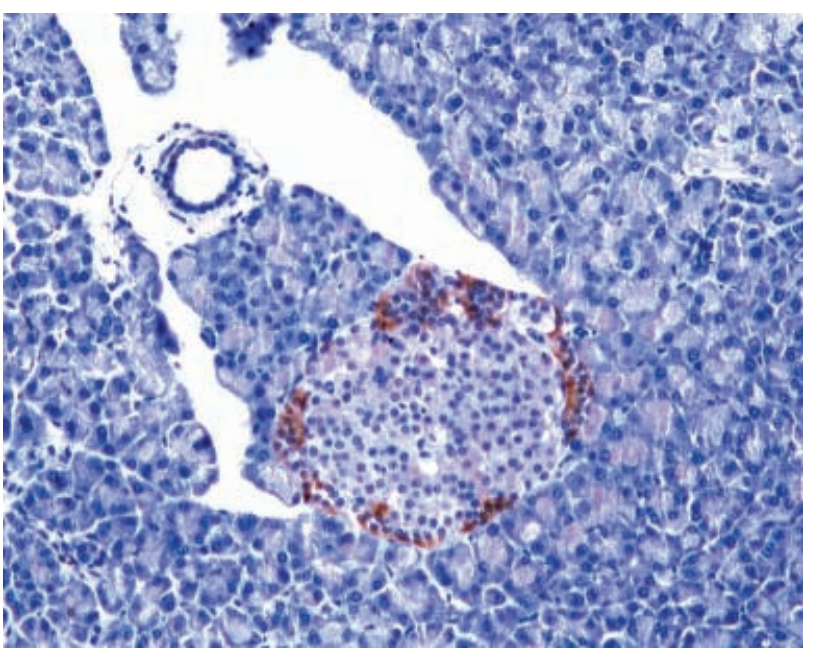

B

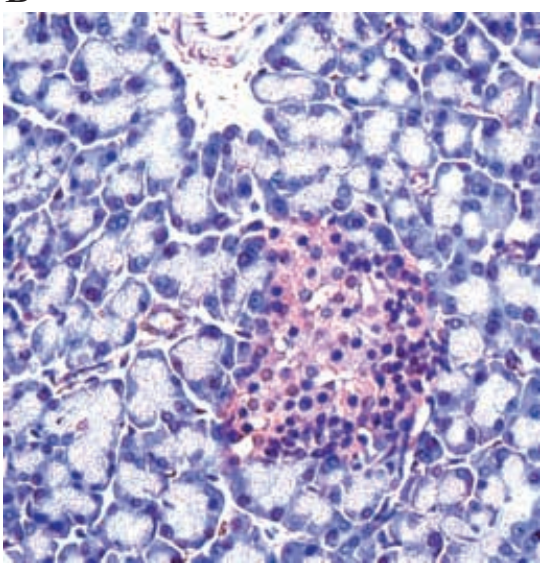

$\mathrm{C}$

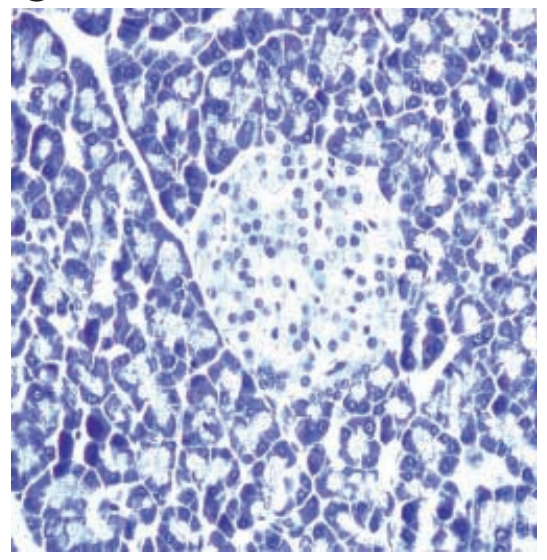

$\mathrm{E}$

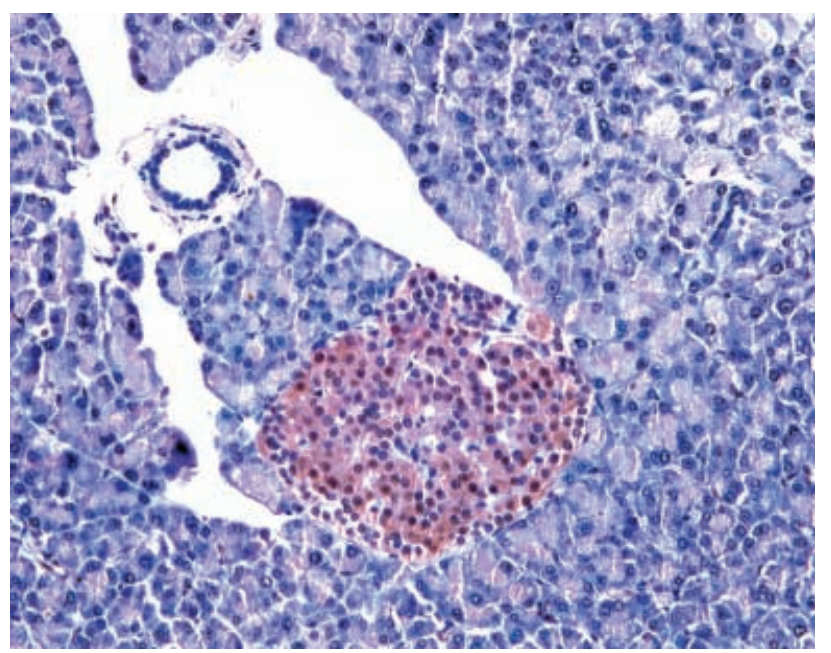

Figure 4 Representative images showing (A) leptin receptor (OB-R) immunoreactivity in an islet of an $A D$ animal fed a control diet, (B) OB-R immunoreactivity in a UN animal fed a hypercaloric diet, (C) absence of staining in an islet following OB-R antibody preabsorption with 10-fold excess of control peptide, ( $D$ and $E$ ) serial sections illustrating leptin and leptin receptor immunoreactivity respectively in a UN animal fed hypercaloric nutrition. The OB-R antibody shown here maps to the amino terminus of the OB-R. There was no difference in OB-R immunoreactivity present between the OB-R antibodies used (data not shown). Magnification: $\times 400$.

has been termed the adipoinsular axis (Kieffer \& Habener 2000). In this concept, insulin stimulates adipogenesis and leptin production in adipocytes whilst leptin inhibits the production of insulin in pancreatic $\beta$-cells. As fat stores increase, rising plasma leptin concentrations reduce circulating insulin levels, thereby directing less energy to the formation of adipose tissue. When, on the other hand, adipose stores decrease, falling plasma leptin concentrations permit increased insulin production, thereby resulting in the deposition of additional fat.

Using the paradigm of fetal programming, we developed a rodent model which displays the phenotype of obesity and metabolic disorders commonly observed in human populations. We apply maternal undernutrition throughout gestation, generating a nutrient-deprived intrauterine environment to induce fetal programming (Woodall et al. 1996). Maternal undernutrition results in fetal growth retardation and in significantly decreased body weight at birth. Programmed offspring develop obesity, hyperinsulinism and hyperleptinemia during adult life, and postnatal hypercaloric nutrition amplifies the metabolic abnormalities induced by fetal programming (Vickers et al. 2000). Our animal model is based on a normal genotype; modifications of environmental factors within a normal physiological range (i.e. maternal undernutrition during fetal development combined with dietinduced obesity during postnatal life) lead to profound obesity and dysregulation of the adipoinsular axis.

In the present study, we showed that birth weights of offspring from UN mothers are significantly lower in 

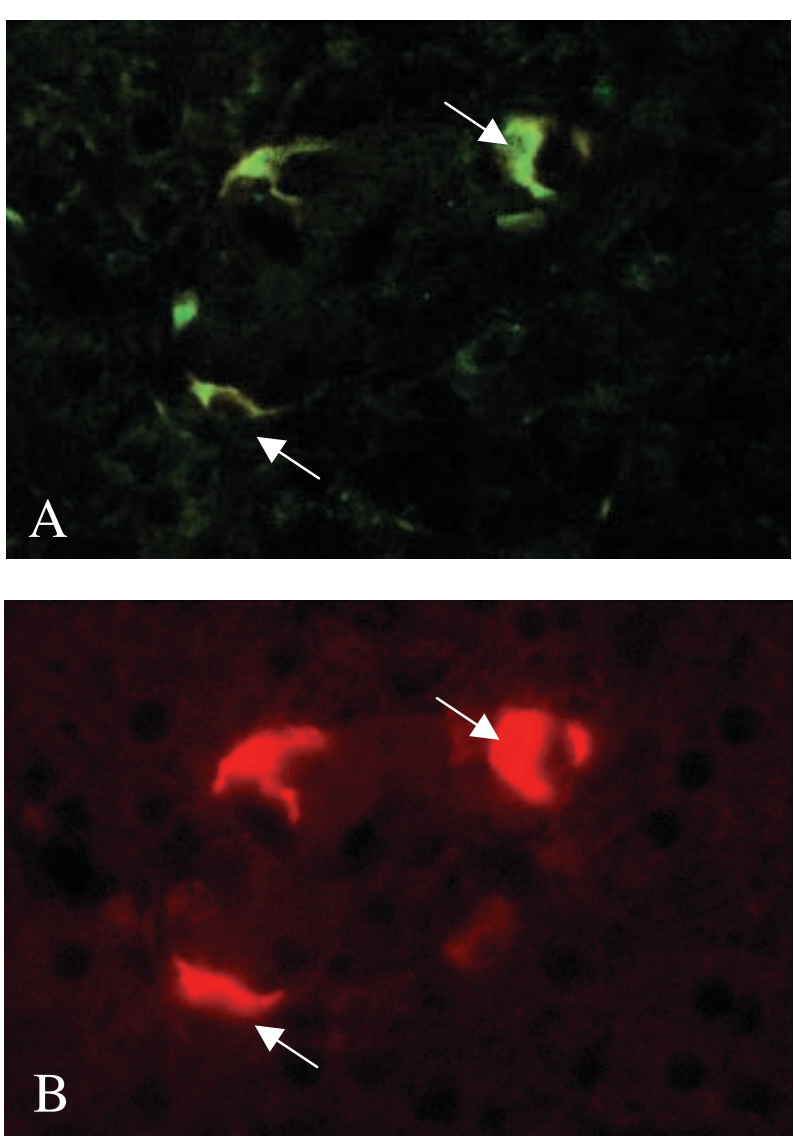

Figure 5 Representative light immunofluorescence photomicrographs showing islets from pancreatic sections labeled with (A) leptin (fluorescein isothiocyanate, FITC) and (B) somatostatin (Texas Red). Sections were examined with a Olympus UV-visible microscope equipped with excitation filters for Texas Red $(568 \mathrm{~nm})$ and fluoroscein $(488 \mathrm{~nm})$. Somatostatin and leptin were co-localized to pancreatic $\delta$-cells at the periphery of the endocrine islet (see arrows for examples). Magnification: $\times 600$. Islet illustrated is that of an AD animal fed a control diet. Pattern of co-localization of leptin and somatostatin was identical in all groups of animals studied.

comparison to the birth weights of offspring from $\mathrm{AD}$ mothers and that the postnatal growth curves are parallel when both groups of offspring are fed on a standard diet. However, programmed offspring (from UN mothers) show apparent catch-up in body weight when they are fed on a hypercaloric diet. Since body length remains significantly lower in programmed offspring and is not altered by the different postnatal diets, the additional weight gain of UN group animals on hypercaloric nutrition reflects the development of profound obesity. The additive effects of programming and hypercaloric nutrition on retroperitoneal fat pad weight observed in the present study support this notion.

In our present study euglycemia was maintained when either of the environmental modifications was used alone.
However, programmed offspring on a hypercaloric diet developed hyperglycemia which suggests that the elevation in plasma insulin levels was not sufficient to maintain glycemic control. Fasting plasma insulin levels increased with increasing obesity, and fetal programming and hypercaloric nutrition had independent effects which were additive when both manipulations were combined. On the other hand, plasma leptin concentrations were increased to a similar extent by both fetal programming and by hypercaloric nutrition, and two-way ANOVA revealed a significant programming and diet interaction when both manipulations were combined. These data suggest that the combination of both environmental modifications leads to amplification of hyperleptinemia. Since Pallett et al. (1997) showed that leptin rapidly inhibits glucose-stimulated insulin secretion in vitro, we propose that fetal programming may lead to $\beta$-cell dysfunction which could be induced by hyperleptinemia. Thus, hyperleptinemia may attentuate insulin secretion so the hyperinsulinism that is observed is not adequate to control blood glucose levels. This notion is supported by a recent report which proposed that in conditions of obesity the prolonged elevation of plasma leptin levels results in dysregulation of the adipoinsular axis and a corresponding failure to suppress insulin secretion (Seufert et al. 1999b). The hyperinsulinism and hyperleptinemia may also be important determinants in the persistence of hyperphagia (Ahima \& Flier 2000). Further studies are required to investigate the neuroendocrine circuitry which regulates food intake in our animal model.

Immunoreactivity for OB-R was evenly distributed throughout the pancreatic islets. Our observations are consistent with other publications which describe OB-R expression in $\beta$ - and in $\delta$-cells of pancreatic islets (Kieffer et al. 1996, 1997, Leclercq-Meyer et al. 1996). We found no evidence of differential regulation of immunoreactivity for OB-R as a result of fetal programming or postnatal hypercaloric nutrition. However, our present study is the first report of leptin localization in pancreatic islets. In programmed offspring, elevated plasma insulin and leptin concentrations were paralleled by markedly enhanced immunolabeling for leptin in the peripheral cells of the pancreatic islets. The immunolabeling for leptin was further increased by diet-induced obesity. Leptin immunoreactivity in pancreatic islets was co-localized with somatostatin indicating that leptin may be secreted in pancreatic $\delta$-cells. We therefore propose that the up-regulation of immunoreactive leptin in pancreatic $\delta$-cells may have a similar paracrine function on pancreatic $\beta$-cells to that known for somatostatin (Strowski et al. 2000). Since hyperleptinemia can be viewed as an endocrine endeavor to reduce insulin secretion through direct action on pancreatic $\beta$-cells (Seufert et al. 1999b), the local increase of immunoreactive leptin in pancreatic $\delta$-cells, as observed in the present study, may be a paracrine mechanism reflecting a further attempt to reduce 
hypersecretion of insulin. This may be a final attempt by the adipoinsular axis to break the vicious cycle of leptin resistance, hypersecretion of insulin, increasing insulin resistance and the progression to adipogenic diabetes.

In summary our observations of close associations between immunoreactive leptin in pancreatic islets, a major rise in circulating insulin and leptin concentrations, and a large increase in fat mass provides in vivo evidence for disturbed endocrine communication between adipose tissue and the endocrine pancreas in the pathogenesis of programming-induced obesity. Furthermore, our rodent model is based on environmental modifications, and not on genetic defects, to induce the postnatal phenotype of obesity and metabolic disorders commonly observed in human populations. Our data suggest that a nutrientdeprived intrauterine environment can trigger permanent dysregulation of the adipoinsular feedback system leading to increased adiposity and prolonged elevation of plasma leptin and insulin concentrations.

Although the present study cannot resolve whether the primary defect is in fat accumulation, leptin signaling or insulin signaling, the hyperleptinemia and hyperinsulinism observed in offspring from UN mothers may be a mechanism induced by the experience of a nutrient-deprived intrauterine environment to store large quantities of triglycerides when food is plentiful. Thus, concomitant hyperleptinemia and hyperinsulinism would create a competitive advantage in preparation for a nutrient-deprived environment to store as much fat as possible when food becomes available (thrifty phenotype) (Hales \& Barker 1992). However, when hypercaloric nutrition persists for long periods of time, as seen in the programmed offspring on a hypercaloric diet in the present study, the hyperleptinemia and hyperinsulinism may lead to adipogenic diabetes.

\section{Acknowledgements}

The authors acknowledge support from the Health Research Council of New Zealand and the National Child Health Research Foundation. We also thank Christine Keven and Janine Street for expert technical assistance.

\section{References}

Ahima RS \& Flier JS 2000 Leptin. Annual Review of Physiology 62 413-437.

Ahren B \& Harvel PJ 1999 Leptin inhibits insulin secretion induced by cellular cAMP in a pancreatic B cell line (INS-1 cells). American Journal of Physiology 277 R959-R966.

Anguita RM, Sigulem DM \& Sawaya AL 1993 Intrauterine food restriction is associated with obesity in young rats. Journal of Nutrition 123 1421-1428.

Barker DJ 1995 The fetal and infant origins of disease. European Journal of Clinical Investigation 25 457-463.
Breier BH, Vickers MH, Gravance CG \& Casey PJ 1996 Growth hormone $(\mathrm{GH})$ therapy markedly increases the motility of spermatozoa and the concentration of insulin-like growth factor-I in seminal vesicle fluid in the male GH-deficient dwarf rat. Endocrinology 137 4061-4064.

Ceddia RB, William WNJ, Carpinelli AR \& Curi R 1999 Modulation of insulin secretion by leptin. General Pharmacology 32 233-237.

Chen NG, Swick AG \& Romsos DR 1997 Leptin constrains acetylcholine-induced insulin secretion from pancreatic islets of ob/ob mice. Journal of Clinical Investigation 100 1174-1179.

Echwald SM, Clausen JO, Hansen T, Urhammer SA, Hansen L, Dinesen B, Borch-Johnsen K \&Pedersen O 1999 Analysis of the relationship between fasting serum leptin levels and estimates of beta-cell function and insulin sensitivity in a population sample of 380 healthy young caucasions. European Journal of Endocrinology 140 180-185.

Emilsson V, Liu YL, Cawthorne MA, Morton NM \& Davenport M 1997 Expression of the functional leptin receptor mRNA in pancreatic islets and direct inhibitory action of leptin on insulin secretion. Diabetes 46 313-316.

Fehmann HC, Bode HP, Ebert T, Karl A \& Goke B 1997a Interaction of GLP-I and leptin at rat pancreatic B-cells: effects on insulin secretion and signal transduction. Hormone and Metabolic Research 29 572-576.

Fehmann HC, Peiser C, Bode HP, Stamm M, Staats P, Hedetoft C, Lang RE \& Goke B $1997 b$ Leptin: a potent inhibitor of insulin secretion. Peptides 18 1267-1273.

Girard J 1997 Is leptin the link between obesity and insulin resistance? Diabetes and Metabolism 23 (Suppl 3) 16-24.

Hales CN \& Barker DJ 1992 Type 2 (non-insulin-dependent) diabetes mellitus: the thrifty phenotype hypothesis. Diabetologia 35 595-601.

Ishida K, Murakami T, Mizuno A, Iida M, Kuwajima M \& Shima K 1997 Leptin suppresses basal insulin secretion from rat pancreatic islets. Regulatory Peptides 70 179-182.

Jackson AA, Langley-Evans SC \& McCarthy HD 1996 Nutritional influences in early life upon obesity and body proportions. Ciba Foundation Symposium 201 118-129.

Jones AP, Pothos EN, Rada P, Olster DH \& Hoebel BG 1995 Maternal hormonal manipulations in rats cause obesity and increase medial hypothalamic norepinephrine release in male offspring. Brain Research, Developmental Brain Research 88 127-131.

Kieffer TJ \& Habener JF 2000 The adipoinsular axis: effects of leptin on pancreatic beta-cells. American Journal of Physiology 278 E1-E14.

Kieffer TJ, Heller RS \& Habener JF 1996 Leptin receptors expressed on pancreatic beta-cells. Biochemical and Biophysical Research Communications 224 522-527.

Kieffer TJ, Heller RS, Leech CA, Holz GG \& Habener JF 1997 Leptin suppression of insulin secretion by the activation of ATPsensitive $\mathrm{K}+$ channels in pancreatic beta-cells. Diabetes $\mathbf{4 6}$ 1087-1093.

Leclercq-Meyer V, Considine RV, Sener A \& Malaisse WJ 1996 Do leptin receptors play a functional role in the endocrine pancreas? Biochemical and Biophysical Research Communications 229 794-798.

Lewis RM, Vickers MH, Batchelor DC, Bassett NS, Johnston BM \& Skinner SJM 1999 Effects of maternal captopril treatment on growth, blood glucose and plasma insulin in the fetal spontaneously hypertensive rat. Reproduction, Fertility and Development 11 403-408.

Lupi R, Marchetti P, Maffei M, Del Guerra S, Benzi L, Marselli L, Bertacca A \& Navalesi R 1999 Effects of acute or prolonged exposure to human leptin on isolated human islet function. Biochemical and Biophysical Research Communications 256 637-641.

Pallett AL, Morton NM, Cawthorne MA \& Emilsson V 1997 Leptin inhibits insulin secretion and reduces insulin mRNA levels in rat isolated pancreatic islets. Biochemical and Biophysical Research Communications 238 267-270. 
Poitout V, Rouault C, Guerre-Millo M, Briaud I \& Reach G 1998 Inhibition of insulin secretion by leptin in normal rodent islets of Langerhans. Endocrinology 139 822-826.

Seufert J, Kieffer TJ \& Habener JF 1999a Leptin inhibits insulin gene transcription and reverses hyperinsulinemia in leptin-deficient $o b / o b$ mice. PNAS 96 674-679.

Seufert J, Kieffer TJ, Leech CA, Holz GG, Moritz W, Ricordi C \& Habener JF $1999 b$ Leptin suppression of insulin secretion and gene expression in human pancreatic islets: implications for the development of adipogenic diabetes mellitus. Journal of Clinical Endocrinology and Metabolism 84 670-676.

Sindelar DK, Havel PJ, Seeley RJ, Wilkinson CW, Woods SC \& Schwartz MW 1999 Low plasma leptin levels contribute to diabetic hyperphagia in rats. Diabetes 48 1275-1280.

Strowski MZ, Parmar RM, Blake AD \& Schaeffer JM 2000

Somatostatin inhibits insulin and glucagon secretion via two receptors subtypes: an in vitro study of pancreatic islets from somatostatin receptor 2 knockout mice. Endocrinology 141 111-117.

Vickers MH, Breier BH, Cutfield WS, Hofman PL \& Gluckman PD 2000 Fetal origins of hyperphagia, obesity and hypertension and its postnatal amplification by hypercaloric nutrition. American Journal of Physiology 279 E83-E87.

Woodall SM, Breier BH, Johnston BM \& Gluckman PD 1996 A model of intrauterine growth retardation caused by chronic maternal undernutrition in the rat: effects on the somatotropic axis and postnatal growth. Journal of Endocrinology $\mathbf{1 5 0}$ $231-242$.

Received in final form 26 March 2001 Accepted 12 April 2001 